\title{
CONCILIACIÓN DE LA VIDA ESTUDIANTIL, FAMILIAR Y LABORAL DE UNA MADRE UNIVERSITARIA
}

\author{
Amparo ALONSO-SANZ \\ Universitat de València (España) \\ M.Amparo.Alonso@uv.es
}

\begin{abstract}
STUDY-FAMILY-WORK-LIFE BALANCE OF A MOTHER ON CAMPUS
Resumen: Esta autoetnografía describe las luchas de una estudiante universitaria que trata de encontrar la conciliación de la vida estudiantil, familiar y laboral. A través de las experiencias de las compañeras, y de las suyas propias, dibuja el perfil de este tipo de alumnado no tradicional. La literatura relacionada con el tema, le permite revisar sus vivencias y repensar las falsas creencias impuestas por la cultura patriarcal. Usando la autoetnografía, la autora pretende contribuir a la reflexión respecto de las necesidades y problemas que afectan a las madres universitarias, debido a una discriminación por razón de género. Además espera alcanzar una mejor comprensión de las voces de otras madres que participan en las investigaciones desarrolladas, relativas a la conciliación.
\end{abstract}

Abstract: This autoethnography describes one college student's struggles trying to find the study-familywork-life balance. Through the experiences of her partners, and her personal experimentation, draws the profile of this type of non-traditional students. The literature on the subject, allows the author to review her lives and rethink the false beliefs imposed by the patriarchal culture. Using autoethnography, the author intends to contribute to the reflection about the needs and problems affecting mothers on Campus, due to gender discrimination. Also expects to achieve a better understanding of the voices of other mothers who participate in researches developed, relating to the conciliation.

Palabras clave: Autoetnografía. Conciliación de la vida estudiantil/familiar/laboral. Maternidad. Educación superior Autoethnography. Study/family/work life balance. Motherhood. Higher education 


\section{Introducción}

"La narrativa forma parte del paisaje de la investigación educativa, a pesar de que su teoría y práctica todavía sea debatida y se investigue sobre qué elementos ayudan a su construcción como por ejemplo los literarios (Coulter y Smith, 2009). En décadas recientes, la narrativa como metodología, ha ido creciendo y convirtiéndose en un método de investigación cada vez más popular. En cualquier caso, todavía necesitamos espacios para muchos tipos de investigación, entre ellos la narrativa autobiográfica (Leggo, 2010). El investigador en su rol de "cuenta cuentos" o narrador, que es fundamental en la cultura académica donde la comunidad intercambia sus historias mutuas, comparte las historias que constituyen la vida individual (Holley y Colyar, 2009). El narrador autobiográfico que establece en lugares públicos nociones generales personales (Sameshima, 2009)" (Alonso-Sanz, 2012: 187).

Esta autoetnografía forma parte de una línea de investigación, sobre la falta de conciliación estudiantil familiar, que se aproxima mediante metodologías de investigación cualitativas, a la población de madres universitarias, sus compañeros y docentes; para dar voz a todos los agentes implicados (Alonso-Sanz, Iglesias Martínez y Lozano Cabezas, 2015, 2016). Mostramos nuestro acuerdo con Hernández, Sancho y Creus (2011) que una de las ventajas de la autobiografía pueda resultar la de reducir las tensiones entre investigador e investigado, ante el riesgo de convertir a los sujetos colaboradores en objetos o de actuar el investigador como voyeur. De este modo, revisando previamente en mi propia vida, las categorías y temáticas sobre las que pretendo investigar; puedo aproximarme a los colaboradores de forma más honesta. Y de igual forma, mejoro la capacidad para recoger, analizar e interpretar sus voces. Consideramos este texto autoetnográfico porque,

"El término autoetnografía se aplica en este caso a un texto que no sólo refleja las fuerzas externas que determinan la experiencia cultural de la autora sino que encierra una importante crítica interna a los valores culturales dominantes dentro del propio grupo" (Bellver, 2001: 257).

Por otro lado desde la propia experiencia, pretendo abrir la reflexión respecto a las necesidades y problemas que nos afectan a las madres universitarias debido a una discriminación por razón de género.

\section{Falsas creencias}

Al acabar el instituto deseaba estudiar Bellas Artes, las recomendaciones familiares me hicieron creer que no me serviría para trabajar de forma bien remunerada. Podría haberlo intentado, pero en mi cultura, si tienes dones y talentos debes aprovecharlos; y eso me hizo creer que todas mis capacidades no se desarrollarían con esa titulación sino con cualquier otra más técnica. Esperé.

Con 21 años había terminado mi primera carrera universitaria, era Arquitecta Técnica y tenía trabajo estable. Podría haberme ido a vivir con mi pareja, llevábamos 3 años juntos y por supuesto lo deseábamos, pero en nuestra cultura estaba asentado que antes debías casarte y antes de eso comprar una vivienda; creímos que esa opción era más segura y responsable. Esperamos.

Yo comencé entonces a estudiar mi segunda carrera universitaria, la licenciatura de Bellas Artes que había decidido aplazar. Así que, durante 6 años, traté de conciliar vida laboral 
y estudiantil. A mitad de estudios, con 23 años, Nacho y yo comprendimos que no merecía la pena esperar más, adquirimos una pequeña casa y nos comprometimos en matrimonio. Podríamos haber tenido hijos, deseábamos formar una familia, pero en nuestra cultura no era normal ser madre y estudiante a la vez; eso nos hizo creer que debíamos esperar. Espe$\operatorname{ramos}^{1}$.

Al finalizar mi carrera académica, y creyendo que no estudiaría nada más en adelante (a pesar de que me fascinaba estudiar), decidimos tener un hijo, y con 27 años me quedé embarazada de Gonzalo. No era demasiado joven (aunque algo más que la media de madres en mi círculo social) ni tampoco demasiado mayor como para temer "que se me hubiera pasado el arroz". Al siguiente curso, motivada por el inicio de una crisis económica que en $2007^{2}$ ya detectamos quienes nos dedicábamos a la construcción, decido reinventarme. Es el momento en que comprendo que puedo reunir mis dos vocaciones en una única profesión, el arte y la docencia, y comienzo a trabajar en el área de Expresión Plástica en la Facultad de Educación de la Universidad de Alicante como profesora asociada, a la vez que mantengo mi trabajo como Arquitecta Técnica, y en adelante también como profesora de pintura a tiempo parcial en Centros Sociales de la tercera edad.

Durante un curso (2006-2007) no estudié nada, había renunciado a la posibilidad de ser estudiante si abogaba por ser madre. En un momento de lucidez, se despertó en mi una capacidad de reflexión crítica y madurez, que me permitió cuestionar la validez de las imposiciones culturales, que hasta el momento había creído que eran decisiones propias ${ }^{3}$. En realidad había esperado, aplazado o ralentizado mis deseos en muchas ocasiones debido a falsas creencias. Pero no era capaz de ver que esas reglas de juego podían ser rotas. Sin embargo, avanzar contra corriente implica un sobre esfuerzo adicional, y supone abrir puertas que habitualmente están cerradas a golpe de autoconfianza, determinación y lucha ${ }^{4}$; pero yo todavía no era consciente de ello.

Iluminada, recordé que sí era posible ser madre y estudiante, había visto ejemplos en el pasado y no me había percatado. Entonces me matriculé de un programa de doctorado en

\footnotetext{
1 Se plantea aquí qué tipo de creencias conforman las ideologías por las que pueden verse afectadas, influidas o condicionadas las universitarias. Pero también nos interesan las respuestas que adoptan ellas frente a las concepciones dominantes: "Los desfases entre el debe ser y la existencia, entre la norma y la vida realmente vivida, generan procesos complejos, dolorosos y conflictivos, en mayor grado si son enfrentados con las concepciones dominantes de feminidad (ideologías tradicionales), porque las mujeres viven estos desfases como producto de su incapacidad personal para ser mujeres, como pérdida y como muerte. Otras pueden encontrar además y simultánea y contradictoriamente, posibilidades de búsqueda y construcción propia y colectiva gratificantes. Cada espacio y cada proceso de desestructuración del ser-de y para-otros, que definen la feminidad, significan una afirmación de las mujeres: son hechos innovadores, hitos de libertad y democratización de la sociedad y la cultura" (Lagarde, 1997: 42).

2 En la actualidad sabemos que el ciclo económico de aquel momento "se marca en dos fases: una primera expansiva que abarca el periodo 2000-2007 y otra segunda de carácter recesivo que comprende el periodo 20072010" (Merino, Somarriba y Negro, 2012: 276).

3 Según Lagarde (1997: 71), los nuevos problemas culturales que aborda la antropología de la mujer dejan al descubierto el reconocimiento y la advertencia de diferencias sociales y culturales entre las mujeres: "surge la evidencia de que algunas características consideradas inherentes a la feminidad en circunstancias diferentes, simplemente no pueden desarrollarse".

Las universitarias que deciden ser madres, o bien las madres que deciden ser universitarias, en ocasiones son observadas como mujeres raras o locas, porque han osado transgredir los escasos patrones culturales dominantes, los hitos de la feminidad, con su particular modo de vida. Y efectivamente las universitarias no pueden desarrollar una de las características consideradas inherentes a la feminidad, como es la maternidad, por darse en circunstancias diferentes; es decir por no darse bajo la exclusividad de dedicarse únicamente a ello sino con la intención de compatibilizarlo con los estudios y/o incluso con el trabajo también.

4 "These voices expressed resistance, courage, and determination in their struggle to balance" (Swaner, 2011: $333)$.
} 
didácticas específicas en la Universidad de Alicante que superé en dos cursos (2007-08 y 2008-09). Era el momento de cambio al Espacio Europeo de Educación Superior (EEES) y comenzábamos a escuchar aquello del lifelong learning ${ }^{5}$ ¿Cómo había podido estar tan ciega? En Altea, mientras estudiaba Bellas Artes, había ido buscando (sin darme cuenta) relaciones de amistad con compañeros que podríamos decir pertenecían a un grupo "no tradicional" de estudiantes. Estos amigos no tenían 18 años como la mayoría de alumnado, tampoco 21 como yo, eran adultos.

\section{Mis referentes entre el alumnado maduro ${ }^{7}$}

Por aquel entonces, Concha, madre de un hijo hiperactivo que ya había superado la adolescencia, maestra de formación, trabajadora incansable, y emprendedora de un negocio inmobiliario propio; encuentra por primera vez un momento para escucharse. Entonces se cuestiona a sí misma sobre qué le apasionaba realmente cuando era joven, halla la respuesta en el arte, y aprovechando que reside en Altea decide matricularse en Bellas Artes.

Fabiola, madre de tres hijos que habían superado la adolescencia, maestra de formación, trabajadora incansable, y emprendedora de un negocio de calzado propio; encuentra por primera vez un momento para escucharse. Entonces se pregunta por qué no había estudiado Bellas Artes, a pesar de haber cursado con éxito fragrante Artes y Oficios (ciclo de formación profesional en aquel entonces), y siguiendo su instinto se matricula en Bellas Artes.

Bibiana, madre de una hija que estaba entrando en la adolescencia, después de renunciar a un negocio familiar que no le reportaba felicidad ni crecimiento personal, después de alargar en exceso el tiempo dedicado al cuidado de otros, toma una importante iniciativa. Decide que es el momento de dar continuidad a unos estudios iniciados en la academia de arte Espiral y que habían continuado desde la educación reglada en un ciclo de formación profesional en cerámica; decide que puede intentar demostrarse a si misma que tiene capacidades intelectuales. Y proponiéndose una meta que inicialmente le parece inalcanzable, se matricula en Bellas Artes.

Isabel, madre de dos hijos adolescentes, trabajadora incansable, y emprendedora de un negocio de importación de mobiliario; se siente insatisfecha con los estudios de psicología inacabados en el pasado. Entonces con la resilencia que le caracteriza, y sirviéndose de vivir en la Marina Alta (comarca donde se encuentra Altea) decide embarcarse en el proyecto de la Licenciatura de Bellas Artes.

Bruna, madre de varios hijos, unos adolescentes y otros (de su marido) más adultos, trabajadora incansable y emprendedora de un negocio de fabricación artesanal de lámparas; comprende que para que sus productos sigan siendo de éxito, exclusivos y atractivos debe mejorar su formación. Entonces aprovechando que Altea se encuentra a unos cuantos kilómetros de su pueblo, decide matricularse de Bellas Artes.

Juana, madre de tres hijos que habían superado la adolescencia, y después de haber trabajado durante años en una lujosa tienda de muebles; se observa sola en casa, sin que ya nadie la necesite. Entonces decide demostrarse a sí misma que es capaz de hacer algo difícil, y se matricula en la Escuela Oficial de Idiomas en chino. Después de superar este reto, com-

\footnotetext{
5 EEES implantado desde el curso 2010/2011 tras la publicación del Real Decreto 1393/2007, centradas “en el proceso de aprendizaje del estudiante, en un contexto que se extiende ahora a lo largo de la vida".

6 "Pregnant and parenting students, a subgroup of nontraditional students, are enrolling in higher education at numbers higher than previous decades. While the majority of students are still between the ages of 18-24, there has been a greater rise in non-traditional students in the past three decades" (Brown y Nichols, 2012: 500).

7 "Research into "non-traditional" students focused on adult, mature, part-time and distance-mode students, women, international students and students from minority ethnic groups" (Bosch, 2013: 6).

"Mature students, in particular, were highly motivated to achieve success in their studies despite the risk of compromising their obligations to employers and family members" (Lowe y Gayle, 2007: 230).
} 
prende que es capaz de cualquier cosa, se empodera y decide matricularse en Bellas Artes porque siempre le había apasionado la belleza y jugar con la estética.

Todos ellas fueron durante años un ejemplo para mi de la posibilidad de ser madre y estudiante a la vez. Todas ellas fueron un ejemplo para mi de la lucha por compatibilizar estudios, trabajo y maternidad. Cada conversación mantenida, sostenía la responsabilidad de la autoexigencia, compartíamos todas nosotras el convencimiento de que podíamos hacerlo, y además hacerlo bien. Los resultados académicos de todas estas amigas eran excelentes ${ }^{8}$ a pesar de contar con pocos apoyos ${ }^{9}$. En cierta medida diría que actuamos como un grupo de apoyo donde todas compartíamos dificultades y actuábamos como sostén de la autoconfianza de cada una ${ }^{10}$. Yo no era madre, ellas sí , y construían -sin que me percatara- un modelo de lucha. Ellas no teorizaban sobre derechos de las mujeres, no reivindicaban políticamente las condiciones de desigualdad a las que se veían sometidas por cuestión de género, no tenían una actitud asentada en la queja, no se miraban a sí mismas como damnificadas por la institución universitaria. Todas ellas, si se miraban, si les daba tiempo a mirarse, era para comprobar los estragos del cansancio, del esfuerzo intelectual y físico, para con un poder mental potentísimo, no conformarse y exigirse ir poco más allá. A pesar de que en esta formación académica se nos enseñaba a discutir críticamente nuestra cultura, los sistemas de creencias imperantes, las desigualdades sociales, los problemas de discriminación... desde los ejemplos de genuinos artistas, ninguna observó que ellas mismas eran víctimas de un sistema que consentía situaciones de desigualdad por razón de género. Todas ellas pertenecían a una generación todavía muy machista, el patriarcado había cegado su capacidad para vislumbrar hasta qué punto ese problema era estructural. Ellas habían luchado por formar parte del colectivo de mujeres inmersas en el mundo laboral retribuido, sin ceder al hombre parte de la responsabilidad de la crianza y el hogar. Ellas, para acceder a dónde habían llegado los hombres, debían hacer un esfuerzo adicional no reconocido. Pero si yo hubiera visto en ellas amargura, nunca me hubiera planteado ser madre y estudiante a la vez, muy al contrario las observaba radiantes, resueltas, y cada año que pasaba un poco más seguras de si mismas, con mayor autoestima, con mayor humildad y mucho más felices. Ninguna de ellas desatendió sus obligaciones en el hogar o como madre, ninguna de ellas renunció a seguir trabajando mientras estudiaban. Sin embargo narraban auténticas proezas para resolver los problemas de conciliación, en ocasiones sentían cargo de conciencia ${ }^{11}$ por no estar entregadas al $100 \%$ a los demás o por haber reducido los ingresos que aportaban al hogar o bien su productividad o bien su rendimiento. Su jornada no era doble, tanto dentro del hogar como fuera ${ }^{12}$, su jornada era cuádruple: para con las/os hijas/os, para con el trabajo

8 "Señalan que compatibilizar trabajo y estudios implica: 'menor tiempo, más esfuerzo físico, mayor rendimiento intelectual', aunque este mismo hecho les obliga a una mejor rentabilidad y organización de su tiempo, que en muchos casos se termina traduciendo en un mayor rendimiento académico en relación con sus compañeros y compañeras más jóvenes" (Jiménez y Márquez, 2014: 5).

9 "Each woman actively sought and found some level of support from someone else from financial support to just words of encouragement" (Buteau, 2007; p.110).

Demers (2014) centrada en aspectos relacionados con la salud de las madres universitarias y el estrés que padecen al tratar de equilibrar vida familiar, laboral y estudiantil, insiste en [1] la importancia del apoyo de la familia, pero especialmente [2] el apoyo de los iguales, de los compañeros de estudio. Lynch (2008) también destaca la importancia del apoyo a la identidad de profesores o asesores, compañeros y familias.

10 "Those with a good balance or who managed to balance the demands made on them received more support from family, friends, colleagues and employers than those with a less stable balance" (Lowe y Gayle, 2007: 231).

11 "El conflicto moral entre sus roles de buena madre y esposa y sus expectativas legítimas de continuar y mejorar su formación" (Jiménez y Márquez, 2014: 5).

12 A la doble jornada al a que se refiere Lagarde (1997: 127): "jornada pública de trabajo productivo, asalariado, bajo contrato y [...] jornada privada de trabajo reproductivo"; habríamos de añadir otras jornadas en el caso de las madres estudiantes, como la jornada formativa. La jornada formativa sería aquella que mediante el apren- 
remunerado, para con el trabajo del hogar, y para con los estudios. Me atrevería a añadir una responsabilidad más, la relacionada con responder adecuadamente a las exigencias implícitas en el matrimonio, un trabajo para con sus esposos. Sin embargo que ellas asumieran con orgullo y alegría el esfuerzo adicional que debían hacer como mujeres para estudiar, no significaba, que no se estuviera produciendo una gran injusticia en el contexto educativo. Al acabar sus estudios todas trataron de dar un giro profesional a su vida, en algunos casos de forma drástica e incluso dramática, pero eran las consecuencias de ser personas más capacitadas, reflexivas, formadas y luchadoras.

Precisamente puedo relatar hasta qué punto su situación era diferente, por el hecho de ser mujeres, cuando la comparo con la realidad de los únicos dos hombres que estudiaban siendo padres.

Pepe nos parecía a todos demasiado mayor, tenía familia y trabajaba en el Ayuntamiento de Benidorm. Rara vez compartía con alguien aspectos relacionados con su familia, nunca conocimos a su esposa o hijos. Nunca le escuchamos hablar de que le faltara tiempo para ir a la compra, poner las lavadoras, dejar hecha la comida antes de venir a la facultad, resolver los conflictos de sus hijos, ni nada parecido. Con él todo parecía sencillo de lograr, ni siquiera el trabajo suponía un problema porque contaba con flexibilidad horaria debido al cargo que ostentaba en el organigrama.

Antonio, padre de una hija escolar y otra adolescente, había amasado suficiente fortuna durante años de dedicación al negocio familiar y a las inversiones, como para dejar pagados sus bienes y en ese momento dedicarse a recoger beneficios. Disponía por tanto de ingresos pero no de cargas laborales acuciantes. Presumía de la relación fabulosa que sostenía con sus hijas, especialmente con la menor a la que le contaba cuentos cada noche; pero rara vez presumía o alababa las funciones desempeñadas por su esposa. Teníamos la suerte de conocer a su mujer, le acompañaba a las inauguraciones orgullosa de los logros de su marido, le admiraba profundamente. Ella le dedicaba, con gran dulzura, todo tipo de cuidados y garantizaba unos ingresos mensuales seguros con su trabajo como docente, ella asumía prácticamente por completo las responsabilidades del hogar y la crianza para que él pudiera desplazarse cada día a la facultad. Él nunca acusó que le agobiaran las tareas del hogar, que le resultara difícil compatibilizarlas con los estudios.

Entre los rasgos comunes ${ }^{13}$ a ellas antes de acceder a Bellas Artes, destaco que: eran adultas, tenían hijas/os que habían superado la adolescencia y a los que no tenían que atender durante tantas horas, trabajaban o habían trabajado de forma remunerada, vivían en pareja, asumían las responsabilidades domésticas en mayor medida que sus parejas, un estado de insatisfacción las condujo a formarse académicamente en una titulación superior, les caracterizaba la determinación y capacidad de trabajo.

Entre los rasgos comunes a ellas durante los estudios destaco que: asumían las tareas académicas de forma responsable, obtenían excelentes resultados en las evaluaciones, conciliaban estudios, familia y trabajo en base a su perseverancia, encontraban apoyo entre las iguales, asumían el esfuerzo adicional que requería ser madres y estudiantes con entusiasmo

dizaje y el estudio, le permite a la madre estudiante, capacitarse para el trabajo productivo; sin embargo también es aquella jornada que limita a la jornada privada, en la medida en que le resta tiempo. Según Lagarde (1997: 128-129) la jornada pública: "Reduce el tiempo de la reproducción o sea de la reposición cotidiana de la mujer misma: para cumplir, le quita horas de sueño, al descanso, a otras actividades. Lo que no puede es disminuir el volumen de trabajo. En ocasiones lo hace en menos tiempo ("se apura"). Lo que se genera es un sobre-trabajo de la mujer y un doble desgaste de su fuerza de trabajo y de su fuerza vital". Del mismo modo podemos pensar que la jornada formativa al restar tiempo a la jornada privada genera otro sobre-trabajo de la mujer y por consiguiente un desgaste adicional de su fuerza de trabajo, de su fuerza vital y de su fuerza intelectual.

13 "Cada mujer se constituye y tiene como contenido, como identidad, esa síntesis de hechos sociales y culturales que confluyen en ella y son únicos, excepcionales pero, al mismo tiempo, por semejanza permiten identificarla con otras mujeres en su situación similar" (Lagarde, 1997: 83). 
y sin reconocerse como víctimas de discriminación por razón de género. Los rasgos diferenciadores respecto a los hombres que destaco son: ellas expresaban de forma verbal explícita y constantemente sus relaciones con los otros miembros de la unidad familiar, las responsabilidades que les suponía, las alegrías que les daban pero también los problemas y dificultades que afrontaban para hallar el equilibrio entre todos sus roles; ellas asumían como propia la responsabilidad del buen funcionamiento del hogar, la familia y la economía; ellos sin embargo asumían como propio el derecho a un tiempo para si mismos mientras no desatendieran su responsabilidad laboral y su aportación económica al hogar.

Al finalizar los estudios tanto ellas como ellos introducían cambios en su desempeño laboral para aproximarse a sus intereses artísticos.

\section{Mi experiencia como madre universitaria}

A mis 28 años (octubre de 2007) nace mi hijo Gonzalo y a la vez comienzo a estudiar el doctorado. Mis amigas habían esperado a que sus hijos fueran mayores para poder estudiar, yo estaba harta de retrasar deseos ${ }^{14}$ y me propongo intentarlo con un bebé recién nacido. Recuerdo como mi marido y yo hacíamos malabares ${ }^{15}$ con los horarios para tratar que nuestro hijo pasara las tardes al menos con uno de los dos. De manera que las tardes que le tocaba la responsabilidad a mi marido yo podía acudir a recibir clases (parecíamos y seguimos pareciendo, en horario laboral, un matrimonio divorciado que se reparte la custodia de los hijos). Nunca tuve una falta de asistencia, mis notas siempre fueron sobresalientes y disfruté plenamente de lo que me enseñaban y de lo que yo aprendía. Cuando las cosas se ponían muy difíciles buscaba refuerzos en mi familia, especialmente en mi madre para que se quedara con el niño; no contábamos por aquel entonces con el apoyo de mi suegro o la madrastra de mi marido.

Las mañanas eran diferentes porque Nacho nunca podía ocuparse del nene, su trabajo no se lo permitía. Yo, como arquitecta técnica ejerciendo como profesional liberal y cotizando a través de un seguro privado no gozaba de baja por maternidad ${ }^{16}$; como profesora asociada en la Universidad de Alicante la baja coincidió con los meses que no tenía docencia pero no se me liberó de la parte proporcional de carga docente en el cuatrimestre en el que la había (un derecho que por aquel entonces desconocía). Los primeros meses, si mi trabajo como aparejadora era de despacho, me quedaba con el bebé acunado entre las piernas mientras hacía presupuestos, o dibujaba en el ordenador, si debía acudir a las obras como dirección facultativa procuraba dejarlo en el despacho con mi hermana arquitecta o incluso lo llevaba conmigo y lo dejaba con algún peón a pie de obra mientras yo subía por los forjados a revisar las ejecuciones, a vigilar la seguridad y salud, y a mantener el control de calidad. A los cuatro meses una señora comenzaba a hacerse cargo del cuidado del pequeño por las mañanas ${ }^{17}$, porque empezaba mi trabajo en la universidad y allí no podía llevarlo conmigo. La

14 Marrades (2002: 19) basándose en datos de la Encuesta de Fecundidad 1999 publicados por el Instituto Nacional de Estadística en enero del 2000 comprueba: "Que las madres daban a luz a partir de los treinta años; y que la media de hijos era de 1 ó 1,5 según países, y en España, en los peores momentos, era de 0,5, situándose en 1,07 en 1999. La conclusión parece evidente: las mujeres se están negando a ser madres, o como mucho, están posponiendo su maternidad de sólo un hijo".

15 En la literatura revisada es común emplear el término "juggle" para referirse a la habilidad desarrollada por las/os madres y padres estudiantes para hacer malabares entre las responsabilidades académicas, familiares y laborales, para tratar de conciliar todos estos roles (Bosch, 2013; Brown y Nichols, 2012; Demers, 2014; Swaner, 2011).

16 Para más información al respecto se puede leer Alonso-Sanz, A. (2009). Por las futuras madres arquitectas técnicas. Boletín Informativo del Colegio Oficial de Aparejadores y Arquitectos Técnicos de Alicante, 75, 8-11. Recuperado de http://www.coaatalicante.org/gcw_new/documentos/Boletin\%2075.pdf

17 Uno de los factores facilitadores para el alumnado mayor, es según Jiménez y Márquez (2014: 5) "la externalización del cuidado mediante la contratación de servicios". 
Universidad de Alicante no contaba (ni cuenta) con servicio de escuela infantil donde poder dejar a mi hijo (como estudiante y/o como empleada), y las escuelas infantiles públicas eran excesivamente caras para unos ingresos que iban mermando con la crisis del ladrillo.

La Universidad de Alicante tampoco contaba (ni cuenta) con una zona para niños, una sala de lactancia, o un parque -a pesar de ser un campus peatonal, ajardinado y bellísimo- donde mi marido o la cuidadora pudieran esperarme con mi hijo mientras recibía o impartía clases. Así que antes de nacer Gonzalo, yo ya había renunciado a la posibilidad de amamantarle, veía demasiados obstáculos para siquiera intentarlo. Pensaba: ¿cómo le voy a amamantar cuando esté en clase de doctorado por las tardes, o en la obra por las mañanas?, ¿cómo voy a respetar una lactancia a demanda si mi horario no solo varía según el día de la semana que tengo o no tengo clases, sino también según los imprevistos que van marcando las obras? Ni mi entorno laboral, ni mi entorno educativo eran family friendly ${ }^{18}$, esto dificultaba enormemente las posibilidades de conciliación y me obligaban a hacer sacrificios que atentaban contra los derechos del menor que había traído al mundo y que por otro lado no podía reclamarlos ${ }^{19}$. Sin darme cuenta estaba siendo víctima de discriminación por razón de género, y en mi empeño por no autolimitarme académicamente ni profesionalmente (ambos aspectos relacionados con el doctorado) renunciaba a una maternidad completa ${ }^{20}$.

En mi segundo año de doctorado, una compañera de estudios y de departamento, Inés Lozano me pidió que participara de una entrevista abierta que formaría parte de su investigación para la tesis doctoral titulada "El discurso de la igualdad de las académicas: estudio de caso en la Universidad de Alicante" (Lozano, 2010). Recuerdo que me preocupaba dejarle claro desde el primer momento que yo no me consideraba feminista, que yo no necesitaba mostrarme extremista ni activista para garantizar mis derechos. Vaya ignorancia la mía en aquel momento, que incapacidad par ver que si la universidad hubiera diseñado medidas para garantizar la conciliación estudiantil familiar ${ }^{21}$ de las madres universitarias, las cosas hubieran podido ser muy diferentes. Qué obnubilación para no darme cuenta de que no estaba en condiciones de igualdad con mis compañeros hombres, por el simple hecho de que la maternidad implicaba no solo culturalmente sino desde luego biológicamente situaciones para mi como mujer que nunca afectarían a mis compañeros varones.

Pero la falta de comprensión no era solamente institucional, el equilibrio que requiere una madre universitaria para hacer frente a sus responsabilidades educativas y de crianza, es especialmente y por encima de todo un equilibrio mental ${ }^{22}$. Y si bien en mi comunidad más próxima podía encontrar apoyos, también desde ella y mucho más si iba abriendo círculos

18 Se entiende por entorno family friendly aquel que cuenta con los servicios y medidas necesarios para que pueda desarrollarse el cuidado de los hijos/as adecuadamente. Estos espacios adaptados a las necesidades de la maternidad son reclamados por algunos investigadores a favor de la conciliación estudiantil familiar (Bosch, 2013; Brown y Nichols, 2012; Demers, 2014; Springer, Parker y Leviten-Reid, 2009; Sallee, 2013).

19 "Hemos de reconocer el hecho palmario de que las criaturas bebés también poseen preferencias aunque no puedan expresarlas verbalmente y por ende no puedan ser actores políticos, y que la lactancia materna es probablemente uno de sus intereses fundamentales" (Massó, 2013a: 183).

20 "La vuelta a la Universidad" por parte del alumnado de edades mayores se caracteriza por la incidencia de desigualdades de género, ya que conforme se incrementa la edad se reduce el porcentaje de mujeres estudiantes entre los grupos de mayor edad. La disolución del proceso de feminización entre las edades mayores sugiere la existencia de barreras de género relacionadas con las dificultades de compatibilización de la familia, empleo y estudios que pueden dificultar a las mujeres incorporarse a las aulas universitaria" (Jiménez y Márquez, 2014: 7).

21 "Aunque en España existe una extensa bibliografía que aborda la problemática de la conciliación entre la vida familiar y laboral (Campillo, 2010; Carrasquer, Borrás y Torns, 2004; Méda, 2002; Salido y Moreno, 2009; Tobío, 2005), su articulación con otras dimensiones de la vida como, por ejemplo, el desempeño de actividades formativas ha sido insuficientemente abordado" (Jiménez y Márquez, 2014: 2).

22 Estupiñán-Aponte y Rodríguez-Barreto (2009) insisten en la importancia de la salud mental de las madres universitarias para "afrontar de mejor manera los diversos problemas que se presentan en la vida" (p.996). 
centrífugamente, encontraba cuestionamientos insidiosos sobre mi postura. Interrogantes a los que aun actualmente me veo obligada a responder. Tenía que escuchar expresiones del tipo: ¡Ah! ¿entonces no le piensas dar teta?, pues es buenísima para el niño, lo mejor sin duda para tener unas buenas defensas; chica, pues no sabes lo que te pierdes por no quererle dar pecho, el vínculo con tu hijo no es igual cuando te toca la piel desnuda que con un biberón; ¿y te piensas perder los primeros meses de cuidado de tu hijo por estudiar cuando llevas toda la vida estudiando? ¿cuándo vas a parar?, yo disfrutaría mucho de cuatro meses de calma para verlo crecer. Nadie le planteaba estas cosas a mi marido, nadie cuestionaba que yo le animara a estudiar cursos y másteres y que él lo hiciera mientras era padre, la presión social no es la misma. Y para poder defenderme contra esos ataques, sin percatarme, me vi obligada a defender las posturas contrarias para no parecer una mala madre, egoísta e insaciable que solo pensaba en su progreso personal. E incluso me veía obligada a responder para justificarme, más me hubiera valido callar, así al menos no hubiera caído en el autoengaño. Cuando en realidad mi contestación tendría que haber sido en forma de otras preguntas más importantes: ¿por qué el Estado no vela por los derechos de las madres estudiantes como lo hace con las mujeres trabajadoras? ¿por qué el Estado se beneficia de la sostenibilidad que garantizamos quienes parimos, sin ofrecernos a cambio una garantía de que ello no nos perjudicará frente a los hombres? ¿por qué debo tener menos oportunidades de progreso académico o profesional por el hecho de querer ser madre? ¿por qué tengo que hacer un esfuerzo adicional que no deben hacer mis compañeros hombres para poder acceder a los mismos puestos laborales dentro de la Universidad? ¿por qué tengo que renunciar a estudiar o renunciar a ser madre, y autolimitarme de un modo u otro ya que es prácticamente imposible compatibilizar estudios y familia? ¿por qué debe sufrir mi hijo las decisiones de una madre que no está dispuesta a autolimitarse?

Sin embargo nunca arrojé estos interrogantes, en cambio me adulteré creyendo que: si dejaba a mi hijo en manos de otras madres ${ }^{23}$ (una cuidadora, su abuela, o su tía), no le estaba perjudicando; que si sustituía la teta por un biberón no le estaba lastimando; que si yo estaba demasiado estresada cuando lo acunaba o alimentaba no se lo iba a transmitir; que si yo renunciaba a un poco de mi quedaría más tiempo para que él no prescindiera completamente de su madre.

En aquel tiempo, en una de mis clases de Educación Artística, se me planteó una situación importantísima: una alumna de Magisterio (plan de estudios en extinción con lo que conlleva para un estudiante descolgarse del grupo que va cerrando cursos) me anunció que estaba embarazada y creía que no podría acabar el curso. Fue la primera vez que comprendí que podía hacer algo al margen de la institución universitaria, era un riesgo que deseaba afrontar por convicción, por empatía (me encontraba en idéntica situación) y por activismo. Animé a su equipo de trabajo para que desarrolláramos un plan que le permitiera a ella trabajar desde casa durante las semanas que necesitara para recuperarse del parto o para disfrutar de su hija; a cambio ella trató durante las semanas previas al parto trabajar más duramente. La animé para que cuando sintiera el deseo de regresar a las clases lo hiciera acompañada de su hija, le dije que podría entrar al aula con la recién nacida y amamantarla allí si era su deseo. Y así ocurrió, su madre la acompañaba a la facultad los primeros días y paseaba con la nieta por el campus, cuando lloraba golpeaba en el cristal de la ventana y la alumna salía a darle la teta. Al poco tiempo ya venía con la bebé las dos horas de clase y la sesión se desarrollaba con normalidad, quizás con algo más de alegría porque a las compañeras de Magisterio en la especialidad de Infantil les encantaba la oportunidad de compartir los cuidados con ella.

23 Lagarde (1997:392) reclama la importancia de las otras madres, que sin ser la biológica-progenitora, desarrollan funciones maternas; como la sierva-madre o las "madres domésticas: las abuelas, las hermanas, las tías, las hijas, es decir, las parientas; las madrastras, las vecinas, las amigas". 
En cualquier caso es importante aclarar el papel que desempeñó mi marido en estos días. Nacho nunca ha sido un florero (objeto de adorno al que hay que quitarle el polvo), apelativo despectivo empleado por algunas amigas para con sus parejas. Nacho y yo acordamos siempre qué era más conveniente para nuestro hijo, para mi y para él; hemos procurado repartirnos el tiempo, las responsabilidades y las tareas lo más equitativamente posible. Y cuando el reparto no ha podido ser más equilibrado se ha debido a condicionantes externos que le han privado de la posibilidad de atender sus deseos paternos en las mismas circunstancias que yo. Ninguno hemos entendido la crianza como una carga ${ }^{24}$.

Resultaba complejo encontrar tiempo de estudio fuera del horario regular de las clases, puesto que no podía restarle horas al trabajo remunerado, a duras penas podía reducir el tiempo dedicado a las tareas domésticas (porque nuestra organización ya era de alto rendimiento), y no deseaba restarle más tiempo a mis hijos cuando mi marido no podía ocuparse personalmente. De modo que la solución pasaba por eliminar horas de sueño, actividades deportivas, momentos para dibujar o pintar o esculpir, encuentros con los amigos y otras actividades sociales ${ }^{25}$. Los fines de semana a las seis de la mañana ya estaba en un local de nuestra propiedad cercano a nuestra casa estudiando, para poderme unir a mi familia a la hora de la comida. Mi constancia me hacía obtener una media de 15 horas semanales bien concentrada y resultó ser suficiente.

Así que decidí seguir adelante y como me apasionaba investigar trasladé mi expediente a la Universitat de València, y con Ricard Huerta como director dimos forma a mi tesis doctoral. Este tránsito de una universidad a otra ralentizó medio año mi defensa, pero en cuanto deposité en secretaría los ejemplares supe que no quería esperar más para tener un segundo hijo. Mi marido insistía que esperáramos a defender la tesis, pero no pude aguantar más y le convencí de que un segundo hijo no obstaculizaría mi avance académico.

Cuando vas echando agua al vaso y ves que tiene capacidad, nunca piensas en que llegará un momento en el que podrá rebosar (dos años más tarde mi mente explotó). Así que yo fui sumando responsabilidades sin encontrar por donde achicar más agua. Embarazada desde junio de 2011, cuando en octubre de ese año defendí mi tesis, la barriga ya era patente. Mi director me decía: no te preocupes porque se note. Yo no quería ningún tipo de trato especial, así que procuré que mi estado de gestación no se percibiera comprándome un vestido negro que disimulaba la tripa a la perfección. Qué ingenua, todos los miembros del tribunal lo sabían, y pude agradecerlo cuando al acabar, mi vejiga disminuida de capacidad no me dio más tregua antes de acudir corriendo al baño.

¿Por qué no debía recibir un trato especial? Me hubiera ayudado poder acudir a alguna tutoría con mi hijo cuando me resultaba dificilísimo dejarlo con alguien para desplazarme $200 \mathrm{Km}$. Me hubiera amparado contar con algún tipo de beca que me permitiera afrontar los gastos académicos, por aquella época mi trabajo de aparejadora a penas dejaba ingresos pero todavía dejaba mucho trabajo. Me hubiera gustado que Gonzalo estuviera presente en la defensa de mi tesis para que le ayudara a entender el tiempo que mi carrera académica le había robado. Me hubiera gustado que con 3 años Gonzalo presenciara el momento más importante de mis estudios universitarios para poder completar el ejemplo -de estudiante y de mujer- que quería ser para él (tal y como lo había sido mi padre para mi cuando estudió su segunda carrera ya con 4 hijos y gracias a una esposa entregada). Me hubiera ayudado mucho una tramitación de mis papeles más ágil para dejar de temer que mi defensa llegara des-

24 "Hoy se reivindica que el cuidado sea asumido también por los hombres, pero no como una condena sacrificial que haya que compartir, sino porque esa esfera contiene importantes valores de los que también aquel sector de la sociedad puede beneficiarse" (Massó, 2013a: 182).

25 "Included the sacrifices that had to be made (sleep, social life, personal interests), the feelings of guilt because there was not much time to participate in activities with the children, and the lack of emotional support from family or friends who thought that going to college was a waste of time" (Buteau, 2007: 112). 
pués del parto, porque la deposité en Marzo y no la pude defender hasta Octubre. Ese tipo de trato especial no hubiera estado nada mal. Afortunadamente no padecí un embarazo de riesgo ni tuve que hacer reposo absoluto, de manera que pude moverme con cierta libertad.

Conforme terminé con la tesis me matriculé del curso de adaptación al Grado de Arquitectura Técnica porque el EEES había transformado mi diplomatura de 3 años en un Grado de 4 años, y esta era la forma de homologar mi título al de los recientes egresados. Estudié este curso de adaptación en la Universidad de Alicante en avanzado estado de gestación, cuando alumbré en Febrero de 2012 estaba en pleno periodo de evaluaciones. Recuerdo que pensé, no pasa nada, voy a poder. Falté un único día a clase, a la siguiente semana dejaba a mi hija Elena en casa de mi suegro (por primera vez iba a cuidar de uno de mis hijos, en realidad su reciente esposa se encargaría). Solamente tenía que ir a clase los viernes de forma intensiva y desarrollar mi Trabajo Final de Grado. Pero junto con mis hermanos tuve que asumir el cuidado de mi madre, ingresada en el hospital para una operación y con un largo periodo de depresión posterior; aquello fue agotador (las cargas familiares no siempre son para con los descendientes también pueden serlo con los ascendientes). Renunciar a la alegría de un bebé para acompañar a un adulto en su infelicidad, era algo con lo que no contaba. De nuevo comprobé que la universidad no contaba con recursos de apoyo a estudiantes con cargas familiares. ¿Qué pasaba? No era la única adulta en el campus, el EEES había reconducido hasta la universidad a muchos egresados maduros, nos exigía una mayor presencialidad, y... ¿no estaba preparada para apoyarnos? Entonces hice mi segundo acto reivindicativo, decidí presentarme a un examen de informática con mi recién nacida; no di opción al profesor, le dije: soy madre, soy estudiante, y además como docente de esta Universidad se que nada me impide acceder a sus instalaciones con mi hija; si llora por hambre saldré, si se despierta saldré, no voy a molestar a ningún compañero, pero quiero hacer uso de mi derecho a examinarme.

Sin embargo pensaba que si yo sola (en realidad en pareja) y voluntariamente había decidido estudiar siendo madre, tenía que asumir las consecuencias, y que la universidad no tenía obligación de facilitarme la conciliación. Ahora veo cómo era de absurdo ese pensamiento. ¿A caso una mujer trabajadora que haya decidido voluntariamente acceder al mundo laboral, tiene que asumir las consecuencias de quedarse embarazada o peor aún de atreverse a buscar el embarazo sabiendo cuáles son las obligaciones contraídas con la empresa que la emplea? Entonces, ¿por qué creemos que una mujer estudiante que haya decidido voluntariamente matricularse en la universidad, tiene que asumir las consecuencias de quedarse embarazada o peor aún de atreverse a buscar el embarazo sabiendo las responsabilidades académicas que tiene?

Si aceptamos que el Estado debe velar por la conciliación laboral-familiar y tomar medidas legales, en ocasiones incluso de discriminación positiva, para compensar las desigualdades estructurales. Si aceptamos que el Estado debe hacerlo además porque se beneficia de las nuevas generaciones que traemos las mujeres al mundo y que harán sostenible el sistema de pensiones. Si defendemos que el Estado debe velar para que se respeten los derechos de las mujeres madres, no solo en las instituciones públicas sino en todas las empresas. Entonces, ¿por qué nadie reclama que el Estado actúe igual con las madres universitarias?, ¿dónde reside la diferencia?, ¿por qué no exigimos que obligue a las universidades públicas y privadas a garantizar la conciliación estudiantil familiar?

Puede que "nosotras" temamos regresar a los valores dramáticos de adolescentes embarazadas involuntariamente, puede que temamos perder las oportunidades de progreso académico por las que tanto lucharon las primeras mujeres que accedieron a los estudios universitarios. Puede que "ellos" teman incentivar los embarazos, puede que crean que las mujeres no estamos educadas para comprender cuándo es el momento para asumir la maternidad con responsabilidad, puede que no interese ayudar a que las mujeres tengan las 
mismas oportunidades académicas que los hombres y con ello tengan una formación equiparable a la misma edad y puedan acceder a los mismos puestos de trabajo.

¿Por qué no tuve mi primer hijo cuando finalicé mi primera carrera universitaria con 21 años, con pareja y empleo estable? Muchas veces me he hecho esta pregunta. Si después he podido comprobar que era posible estudiar (un doctorado, la tesis y curso de adaptación a Grado), trabajar (en 3 empleos a la vez) y ser madre, ¿por qué no lo intenté antes, al matricularme de Bellas Artes, cuando era más joven y tenía más energía? La respuesta ha sido sencilla, la he encontrado después de revisar la literatura referida al tema. No creí que pudiera intentar ser madre universitaria antes porque nada, absolutamente nada en mi entorno, me daba a entender que fuera una idea socialmente aceptada, académicamente posible, legislativamente garantizada, económicamente factible, o estructuralmente facilitada mediante recursos. Entonces no tenía amigas universitarias madres, porque además Arquitectura Técnica era una titulación mayoritariamente masculina. No veía, ni todavía veo en la universidad: grupos de apoyo o asociaciones de madres universitarias, adaptaciones curriculares para el colectivo de madres, bajas de maternidad para estudiantes, condiciones de matrícula o de contratación de seguro adaptadas, flexibilidad horaria o prioridad en la elección de turnos, grupos y horarios para madres, respeto por los tiempos necesarios durante embarazos de riesgo o el puerperio, ofertas de trabajo a tiempo parcial en la universidad para madres universitarias en estado de desempleo, ayudas o becas o financiación para madres universitarias, cambiadores para bebés, salas de lactancia o sofás en zonas abiertas donde lactar cómodamente ${ }^{26}$, espacios family friendly, zonas de juego infantil, escuelas infantiles con plazas garantizadas para estudiantes ${ }^{27}$, etc.

Deseo profundamente que algún día, si mi hijo Gonzalo y mi hija Elena deciden estudiar en la universidad, y desean ser padres, puedan optar a ello con garantías de una adecuada conciliación familiar estudiantil. Y especialmente, que mi hija no sufra discriminación alguna en la institución universitaria por razón de género ${ }^{28}$.

\section{Referencias bibliográficas}

Alonso-Sanz, A. (2012). Autobiografía de una profesora de Educación Artística. En J. I. Rivas, F. Hernández, J. M. Sancho, C. Núñez (Coords.), Historias de vida en educación: Sujeto, Diálogo, Experiencia (pp. 187-192). Barcelona: Dipòsit Digital UB. Recuperado de http:// hdl.handle.net/2445/32345

Alonso-Sanz, A., Iglesias Martínez, M. J. y Lozano Cabezas, I. (2015). La conciliación estudiantilfamiliar y el proceso de enseñanza-aprendizaje en Educación Superior: un estudio cualitativo. Educatio Siglo XXI, 33(3), pp. 223-244. DOI: http://dx.doi.org/10.6018/j/241001

Alonso-Sanz, A., Iglesias Martínez, M. J. y Lozano Cabezas, I. (2016). Propuesta de regulación de la conciliación estudiantil-familiar en la Educación Superior. Revista de Educación y Derecho, 13, 57-73. Disponible en http://revistes.ub.edu/index.php/RED/article/view/15501

\footnotetext{
26 Desde el lactivismo contemporáneo (Massó, 2013b) muchas personas lactantes prefieren los lugares públicos antes que ser ocultadas en una sala de lactancia: "Si bien es cierto que algunas madres prefieren contar con algún lugar de intimidad cuando lactan, las salas de lactancia pueden mostrar el rostro deletéreo en su contrapartida 'no se puede hacer en público', y entendiendo que hay un lugar designado para ello" (Massó, 2013a: 194).

27 Por citar solo algunas de las posibles medidas para la conciliación familiar estudiantil que ya son reivindicadas desde algunos países desarrollados (Bosch, 2013; Brown y Nichols, 2012; Lowe y Gayle, 2007; Rosende, 2011; Springer, Parker y Leviten-Reid, 2009; Vryonides y Vitsilakis, 2008).

28 "La presencia activa en la sociedad. Es importante enfatizar la importancia de la Universidad como generadora de opinión y de crítica social. No existe otro sector con la misma capacidad de creación de conocimiento y su misión no debe finalizar en ese punto, debe también introducir elementos de reflexión en el debate social frente al mismo a sus orígenes y a sus consecuencias" (Andrés, 2001: 5).
} 
Andrés, J. M. (2001). Los nuevos retos de la Educación Superior. Revista Fuentes, 2. Recuperado de http://institucional.us.es/revistas/fuente/2/(Microsoft\%20Word\%20-\%20LOS\%20NUEVOS\%20RETOS\%20DE\%20LA\%20EDUCACI.pdf

Bellver, P. (2001). La infancia como pretexto: autobiografía, etnografía y autoetnografía en Hoyt Street de Mary Helen Ponce. Estudios Ingleses de la Universidad Complutense, 9, 253-271. Recuperado de http://revistas.ucm.es/index.php/EIUC/article/view/EIUC0101110253A

Bosch, B. (2013). Women who study: balancing the dual roles of postgraduate student and mother (Tesis doctoral inédita). Edith Cowan University, Western Australia, Australia.

Brown, V. y Nichols, T. R. (2012). Pregnant and parenting students on campus: policy and program Implications for a growing population. Educational Policy, 27(3), 499-530. Consultado el 10 de abril de 2014 en http://epx.sagepub.com/content/27/3/499.full.pdf+html DOI: $10.1177 / 0895904812453995$

Buteau, R. (2007). Balancing Acts: A Phenomenological Study of Single Mothers Who Are Successful Students in Higher Education. En L. Servage y T. Fenwick (Eds.), Learning In Community: Proceedings of the joint international conference of the Adult Education Research Conference (AERC)(48th National Conference) and the Canadian Association for the Study of Adult Education (CASAE)/l'Association Canadienne pour l'Étude de l'Éducation des Adultes (ACÉÉA) (26th National Conference), (pp. 109-114). Recuperado de http://casae-aceea.ca/ casae/sites/casae/archives/cnf2007/Proceedings-2007/ AERC\%20CASAE\%20Proceedings-complete-2007sml6.pdf\#page $=575$

Demers, D. (2014). Back to school: the balancing act graduate student mothers play between home and school (Tesis doctoral inédita). Southern Illinois University Carbondale, Illinois, Estados Unidos.

Hernández, F., Sancho, J. y Creus, A. (2011). Lo que hemos aprendido a la hora de llevar a cabo historias de vida a partir de cuatro proyectos de investigación. En F. Hernández, J. M. Sancho y J. I. Rivas (Coords.), Historias de vida en educación: biografías en contexto (pp. 47-56). Barcelona: Universitat de. Recuperado el 25 de febrero, 2011, en http://hdl. handle.net/2445/15323

Jiménez Rodrigo, M. L. y Márquez Lepe, E. (2014). Ir a la Universidad después de los 30: dificultades y factores facilitadores. Aula Abierta 42, 1-8.

Kostopulos Nackoney, C., Munn, S. L. y Gallagher, S. J. (2007). Becoming Scholarly Writers: An Autoethnography of Three Emerging Scholars. En L. Servage y T. Fenwick (Eds.), Learning In Community: Proceedings of the joint international conference of the Adult Education Research Conference (AERC)(48th National Conference) and the Canadian Association for the Study of Adult Education (CASAE)/l'Association Canadienne pour l'Étude de l'Éducation des Adultes (ACÉÉA) (26th National Conference), (pp. 445-450). Recuperado de http://casae-aceea.ca/ casae/sites/casae/archives/cnf2007/Proceedings-2007/ AERC \%20CASAE\%20Proceedings-complete-2007sml6.pdf\#page $=575$

Lagarde, M. (1997). Los cautiverios de las mujeres: madresposas, monjas, putas, presas y locas. México: Universidad Nacional Autónoma de México. (Edic. Orig. 1990).

Lynch, K. D. (2008). Gender roles and the American academe: a case study of graduate student mothers. Gender and Education, 20(6), 585-605. Disponible en: http://dx.doi. org/10.1080/09540250802213099

Lowe, J. y Gayle, V. (2007). Exploring the work/life/study balance: the experience of higher education students in a Scottish further education college. Journal of Further and Higher Education, 31(3), 225-238. DOI: 10.1080/03098770701424942

Lozano, I. (2010). El discurso de la igualdad de las académicas: estudio de caso en la Universidad de Alicante (Tesis doctoral inédita). Universidad de Alicante, Alicante, España.

Massó, E. (2013a). Lactancia materna y revolución, o la teta como insumisión biocultural: calostro, cuerpo y cuidado. Dilemata, 11, 169-206.

Massó, E. (2013b). Deseo Lactante: sexualidad y política en el lactivismo contemporáneo. Revista de Antropología Experimental, 13, 515-529.

Merino, M. C., Somarriba, N. y Negro, A. M. (2012). Un análisis dinámico de la calidad del trabajo en España. Los efectos de la crisis económica. Estudios de Economía Aplicada, 30(1), 261-282. 
Real Decreto 1393/2007, de 29 de octubre, por el que se establece la ordenación de las enseñanzas universitarias oficiales. Extraído el 21 de julio de 2014, de http://www.boe.es/boe/ dias/2007/10/30/pdfs/A44037-44048.pdf

Rosende, M. (2011). Perspectiva comparada: medidas de conciliación de la universidad de Lausanne para el personal académico y el personal de la administración y servicios. Revista Interdisciplinar de Estudios de Género, 1, 31-44.

Sallee, M. W. (2013). Gender Norms and Institutional Culture: The Family-Friendly Versus the Father-Friendly University. The Journal of Higher Education, 84(3), 363-396. Disponible en http://muse.jhu.edu/login?auth=0\&type=summary\&url=/journals/journal_of_higher_ education/v084/84.3.sallee.html

Springer, K. W., Parker, B. K. y Leviten-Reid, C. (2009). Making Space for Graduate Student Parents. Practice and Politics. Journal of Family Issues. doi:10.1177/0192513X08329293. Disponible en: http://jfi.sagepub.com/content/early/2009/01/07/0192513X08329293.full. pdf + html

Swaner, J. (2011). The hijacking of higher education for women in postwelfare America: a study of underserved and invisible lowincome mothers on campus (Tesis doctoral inédita). University of Utah, Utah, Estados Unidos.

Vryonides, M., \& Vitsilakis, C. (2008). Widening participation in postgraduate studies in Greece: mature working women attending an e-learning programme. Journal of Education Policy, 23(3), 199-208. DOI: 10.1080/02680930801923781 